\title{
Applying Mural Paintings to Restore the Luster of Archeological Parks in Alexandria, Egypt
}

DOI: $10.21625 /$ archive.v1i1.107

\author{
Eman Ahmed Ramzy Elgendy ${ }^{1}$ \\ ${ }^{1}$ Department of Painting (Mural Painting), Faculty of Fine Arts, Alexandria University, Alexandria, Egypt
}

\section{Keywords}

Mural painting; Mosaic Alexandria; Zoo; Parks

\begin{abstract}
Historical, archeological parks such as Antoniadis garden, Al-shallalat gardens and the zoo are important assets in the city of Alexandria, Egypt. These parks suffer from severe neglect, damage and encroachments of street vendors. This study aims to find aesthetic solutions to improve these parks as part of Alexandria's cultural heritage on the nationl and global levels. Mural paintings could be used to beautify the entrances of these parks along with the seating units, garbage bins, and water tap basins. This mural painting process could be well suited with the architectural styles of these parks to preserve their identity and still fit within the history and civilization of the ancient city of Alexandria. This will protect the historical features of these parks and make them touristic destinations instead of being abandoned and neglected over time.
\end{abstract}

\section{Introduction}

During ancient civilizations, humans knew and practiced the art of landscaping gardens. This art was continuously developed and its practice was spread to different countries as a means of entertainment. Landscaping was practiced in public spaces, private gardens, botanic museums and specialized gardens.

Alexandria was the home of successive civilizations due to its unique location on the Mediterranean sea. Alexander the great founded the city of Alexandria in 331 B.C. He commissioned the architect Dinokrat for city planning. The city planning process of Alexandria was characterized by the extension of its streets in straight lines from East to west and from north to south to intersect in right angles with two main streets in the middle. One of them traverses the city from East to West and is now known as Alhoria street. The other one traverses the city from the north to south. Some chroniclers believe that this street is the current Elnabi Daniel Street.

After the death of Alexander the great, his Empire was fragmented among three of his army commanders where Ptolemy (285-246 BC) and his family ruled Egypt for the next three centuries. In this period, the new city of Alexandria was born to become the cultural and intellectual capital of the world.

The city was divided into several districts, most notably the royal district which was wide with many royal palaces and had a zoo, wisdom house and a library. During that same time, the city was known for its parks and white marble columns during the Ptolemaic Kingdom period. Alexandria currently has a number of important historical parks that are considered part of its cultural heritage, particularly Antoniadis garden, Aalshallalat garden and the zoo.

El-Nozha park is considered the most important one in Alexandria. It was founded during the Ptolemies period (300 BC) but it was later divided into sectors. Starting from the period of Mohamed Ali (1805-1848) the development of this park began. The khedive Ismail (1863-1879) paid more attention to broaden this park, and it later became the most famous destination in Alexandria that included several gardens: 
1. Antoniadis garden: In 1860, the Greek Tycoon John Antoniadis who lived in Alexandria commissioned the French artist Paul Richard to create a garden around his palace similar to the Gardens of Versailles in Paris on approximately 45 acres of land. After the death of Antoniadis (1918), his son gave the palace and the gardens to the mayor of Alexandria, according to his father's will. This place is currently known as "Antoniadis gardens", one of the most important botanical gardens in Egypt.

2. The Zoo: It was established in 1921 on part of El-Nozha Park.

3. The rose: This garden was established in 1928 on 5 acres of land. It contains a varieties of roses, trees and rare plants.

The Zoo of Alexandria is one of the parks that are considered part of Alexandria's cultural heritage. It has an artificial lake for water birds, a tower to see all the landmarks of the park, and a museum. It is a semi-natural environment for Zoo animals. This garden contains many rare animals, birds and reptiles. This zoo has suffered from demolition, neglect and abuse by visitors and vendors.

There are many countries that have established organizations to rehabilitate and develop historic places and develop specifications for maintaining the roots and ancient history of the place. This is done until officials have implemented strategies to regain the identity of most places and make sure it coincides with the city's urban planning.

\section{Aim of the work}

This research aims to shed light on potential ways to restore the neglected historical parks and gardens in Alexandria which are considered as iconic national treasures. The recreation of these parks will attract native visitors and tourists visiting Alexandria. This will improve the community's behavior, way of thinking and artistic sense. This research will deal with the Zoo as an example. It aims to find aesthetic solutions to improve these parks as part of Alexandria's cultural heritage on the nationl and global levels. Mural paintings could be used to beautify the entrances of these parks along with the seating units, garbage bins, and water tap basins.

\section{Methods}

Several photographs were taken of the different architectural units of the Zoo including the entrances, seats, the shade, water basins as well as dustbins. Data about the mosaic from the Graeco-Roman period were collected. The Adobe Photoshop CS5 computer program was used to apply the mural painting treatment on the selected photos. The mural painting designs which depend on the botanic component and geometric units were inspired from the Graeco-Roman period in accordance with the surrounding environment and in proportion to the history and civilization of ancient Alexandria without changing any architectural characteristics. This will emphasize the vision emanating from the city's cultural heritage. There was also a conideration to use colors in proportion to natural elements in order to achieve consistency, chromatic harmony, unity and coherence between all elements of the garden.

\section{Results}

After applying the mural treatment on the selected architectural elements, the following results were obtained:

Figure (1a): Shows one of the current entrances of the park. It consists of the stairs that lead to the Swan Lake. These stairs are composed of a horizontal surface of the step (Tread), the vertical surface of the step (Riser), and a protection side barrier (Hand rail). There are mezzanines of various dimensions on either side of these barriers.

Figure (1b): Shows the same entrance after applying the suggested mural treatment. The design was inspired by the Roman mosaics acanthus spiral which wrapped spirally covering the front surface of the mezzanines. These flowers were repeated in smaller sizes in proportion with the surface area of the steps of the treated stairs and in reciprocal directions corresponding and developed with the motion of the steps. The side barriers (Hand rail) and the mezzanines were covered with monochromic mosaic depending on the dynamic motion of the applied mosaic pieces.

Figures: (2a), (2b), (3a), (3b) show the footpath containing taps and basins. The suggested mural design was inspired by the mosaic floor found in Zeugma city (Turkey). This city was founded by the army of Alexander the great. It is one of the cities of the Roman Empire that sank under the waters of the flood waters of a series of dams on the Euphrates. The design depended on circular geometric shapes of repeated rings surrounding the water basin, each ring was outlined with decorative braids and corresponding to the circular footpath under the water basin.

The water basins were treated using various mural painting designs including decorative braids corresponding to the framework of the circular footbath or with incomplete decorative stars reflecting the star in the center of the circular footbath in a simplified manner. 
Figure: (4) shows a view of a park seat facing the bird house before (Fig. 4a) and after the suggested mural treatment (Fig. 4b). The seats have an important function for the Park visitors either to rest, to eat or to enjoy sightseeing of the garden while sitting. Therefore, the functional significance was taken into account from the beginning. The design was derived from the views of birds at one of Romanian palaces which had birds covering the sides of the seat with botanic units of spiral and interlacing plant leaves and grapes to give a complete vision. The seating bench was covered with simple geometric elements in the form of complex circuits which resulted in other geometric shapes to be in harmony with the curves of the branches of plants on the side of the seat.

Figure (5a): shows a scene of one of the current sunshades of the garden associated with seating units. These sunshades with associated seats are widely spread all over the Park.

Figure (5b): the same previous sunshade with associated seast after applying the suggested mural treatment. The design was inspired from the Roman ceiling and arches mosaic in the form of climbing grape plant branches which wrapped and covered the inner surface of the sunshade. This design is in harmony with the external design of the sunshades which were inspired by the shape of the trees.

Figure (6a): Shows the shape of a current dustbin hanging on an iron fence surrounding the plants in the garden.

Figure (6b): Shows a proposal for a dustbin in the Park in the form of a simple geometric shaped box containing the trash basket inside it for easy cleaning and emptying regularly. The front surface of the box is covered with a mosaic where the design was inspired by a tulip and buds in addition to a strip of decorative braids that outlined the edge and covered the sides of the box. These boxes could be distributed in appropriate distances.

Figures (6c\&d): Show two proposals for dustbins inspired by a Roman sculpture of a bird covered by mosaic.

As these architectural elements are found outdoor, they are subjected to different atmospheres that may affect the murals applied. Therefore materials used in the mural treatments should resist the climatic and environmental factors of Alexandria to retain its state as long as possible. These materials should be natural and suit the architectural surface and function. Pressure-resistant materials as marble, granite, stones or gravel should be used for stairs and floors. In the same time the materials used for the surfaces that permanently exposed to water as basins should be of suitable type. For seats the materials should be suitable for the purpose without disruption of the function of the architectural element.

\section{Conclusion:}

Restoring the luster of the zoo of Alexandria is not only for its environmental and historical importance, but also for its social and touristic importance, as it is the only one for the visitors in Alexandria and the neighboring territories.

The main result of the study is summarized in maintaining the remainder of these iconic gardens which reflect the history and othe cultural mission of Alexandria across the eras to avoid the disappearance or fading of the features and characters of the city. The restored gardens should attract more visitors and became a tourist destination instead of being abandoned and neglected over time.

\section{Recommendations:}

- Monitoring these iconic gardens in Egypt that are considered touristic places that may attract local and foreign tourists.

- Preparing developmental and rehabilitation plans for the restoration and maintenance of the archaeological and historic gardens to recover their beauty without affecting their features. This will help to achieve aesthetic foundations of values of poise, rhythm, proportion and unity as well as the relationship between the architectural elements of space and color relationships as a fundamental value to those parks.

- Pay attention to the art of landscaping gardens because of the artistic and architecture value it adds to the place

- Legal and administrative procedures must be implemented to maintain these gardens and regulate their uses.

- Raising awareness and arranging activities that highlight the value of these parks. Arrange visits and prepare information brochures about their historic importance and activities.

- Set a code of Specifications to beautify Alexandria, preserve its cultural pattern and to harmonize between architecture and other arts.

- Combine all governmental and non-governmental organizations, civil society and individuals to preserve the historic buildings and monuments as a memory of the city.

- Improve the behavior of individuals through media to improve public culture. 
- Employment of developmental programs and community service for the protection of the Alexandria's heritage.

- Promote these gardens as a touristic destination to increase national income. 


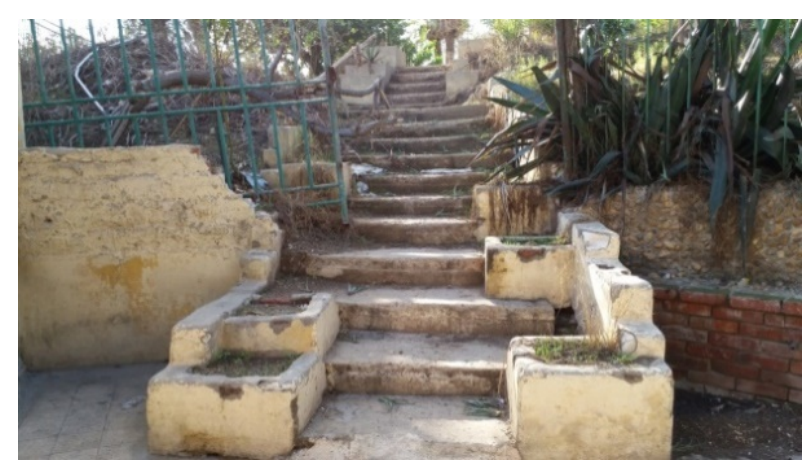

Figure 1a. Showing one of the current entrances of the zoo of Alexandria

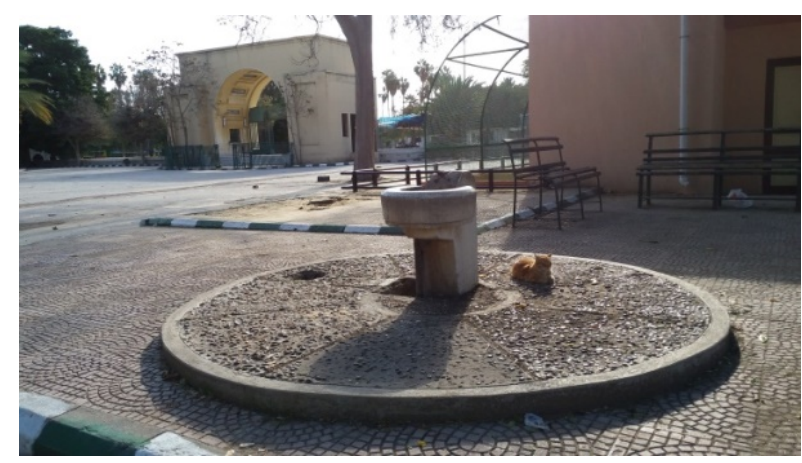

Figure 2a. Showing one of the current entrances of the zoo of Alexandria

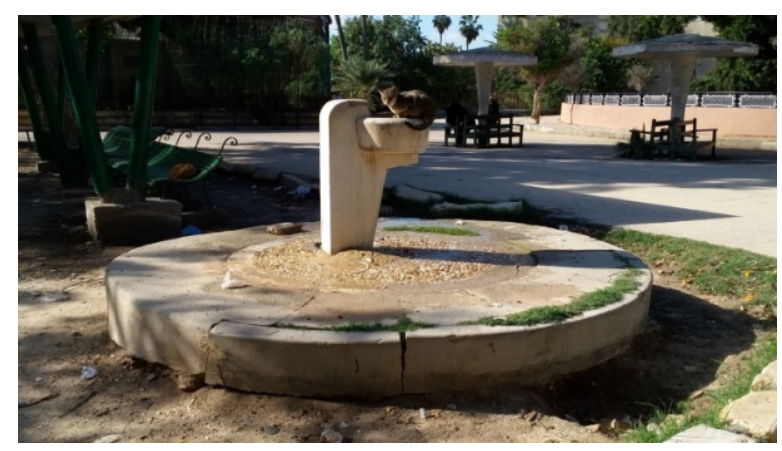

Figure 3a. Showing another one of the current water basin in the zoo of Alexandria

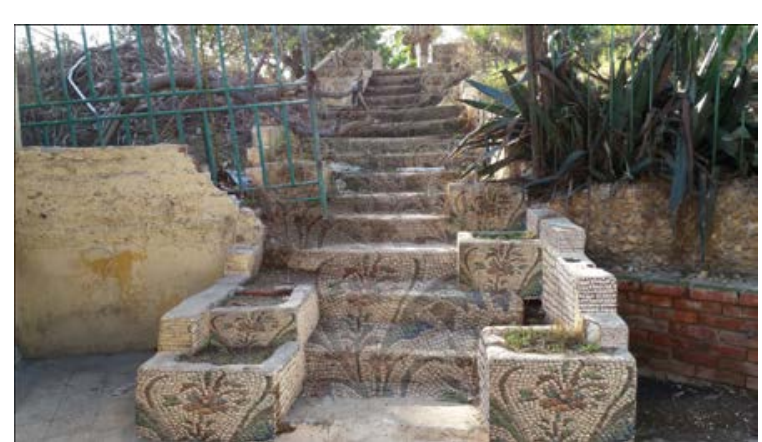

Figure 2b. Showing The entrances of the zoo after applying mural painting

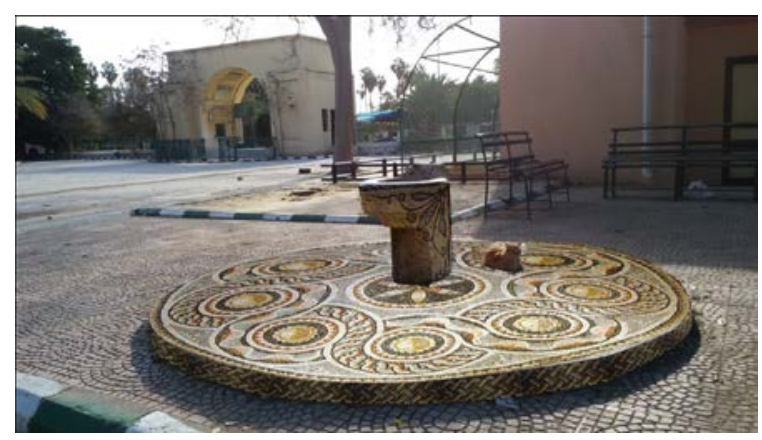

Figure 2b. Showing The entrances of the zoo after applying mural painting

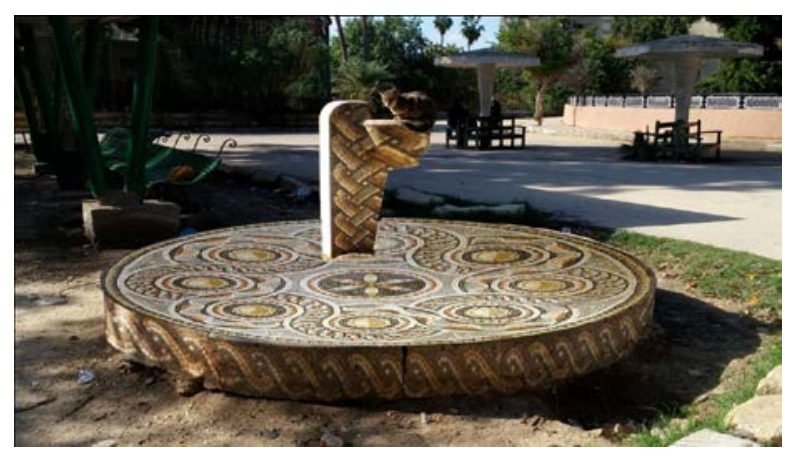

Figure 3b. Showing the previous water basin after applying mural painting

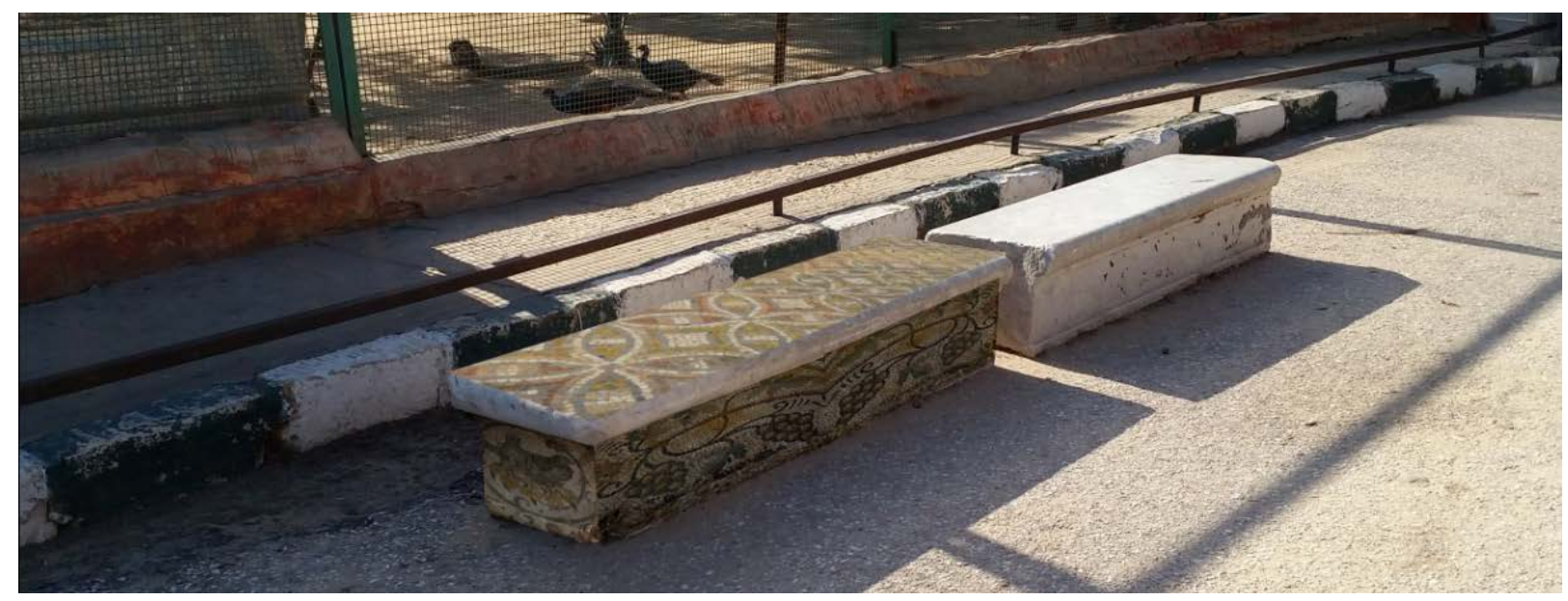

Figure 4a. Showing two seats before and after applying mural treatment. 


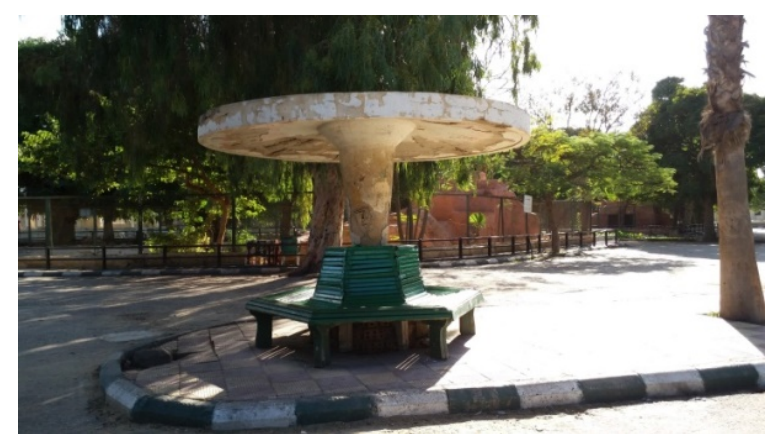

Figure 5a. Showing one of the current sunshade and its associated seats in the zoo of Alexandria

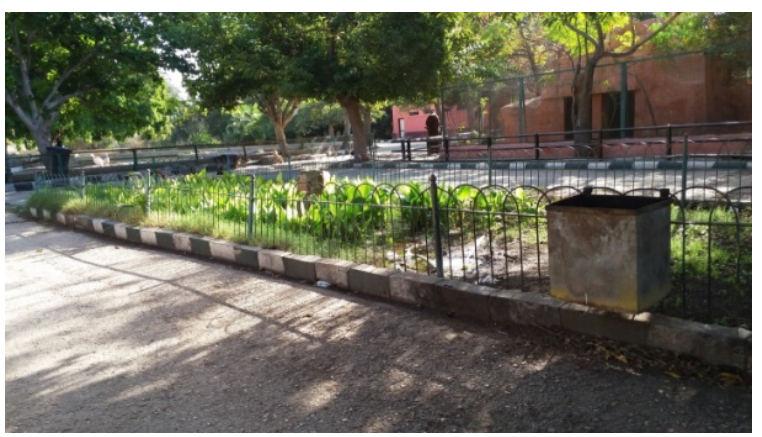

Figure 5a. Showing one of the current dustbin the zoo of Alexandria

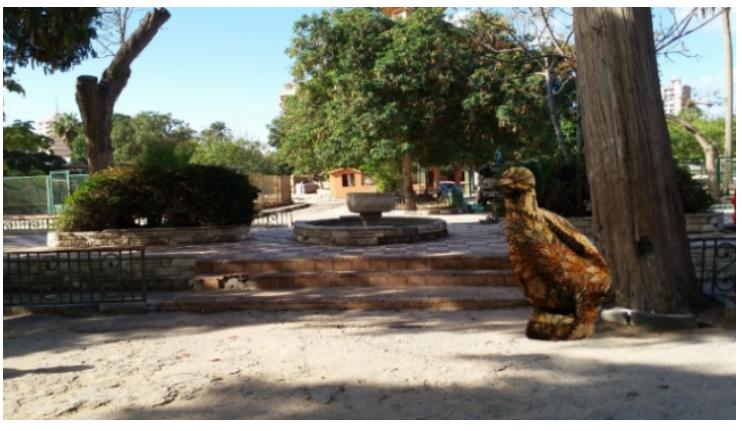

Figure 5c. Showing another suggestion for a dustbin treated with

\section{References}

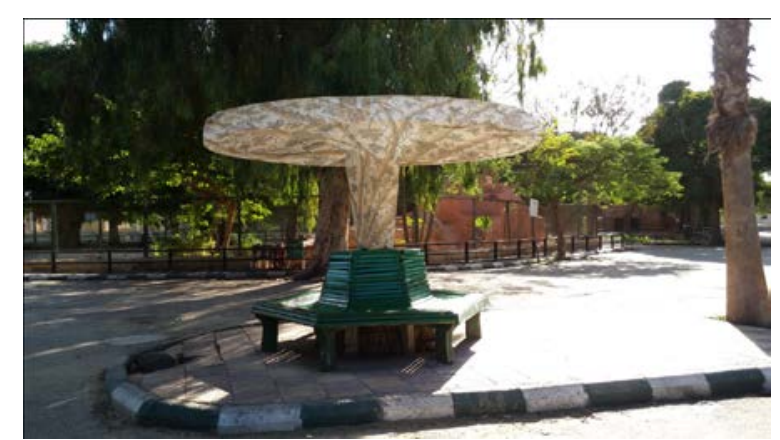

Figure 5b. Showing the previous sunshade after applying mural treatment

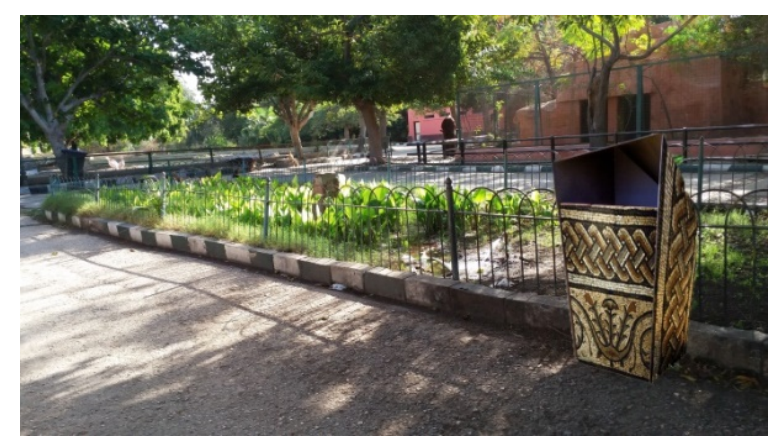

Figure 5b. Showing a suggestion for a dustbin treated with mural painting

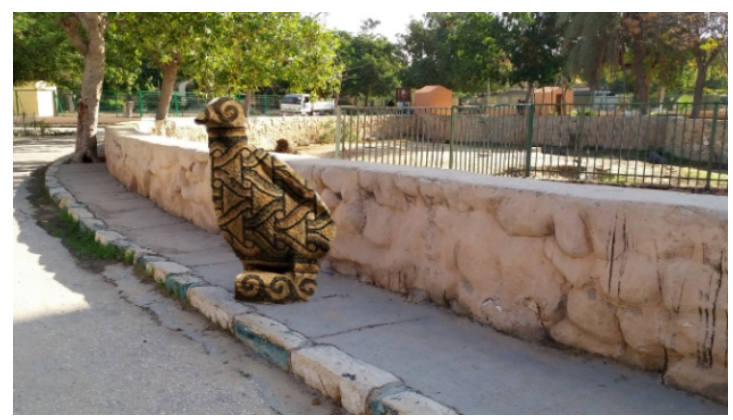

Figure 5b. Showing a third suggestion for a dustbin treated with mural painting

1. Abdelkafi J. Patrimoine culturel et identités de la Méditerranée contemporaine, Patrimoines Partagés de la Méditerranée; 2014

2. Carvalho,P, Silva, S. Historic gardens: heritage and tourism CEGOT - University of Coimbra "XII World Leisure Congress", held in Rimini (Italy); 2012.

3. Elsheikh AZ. (2015). (الاء زكى الثيخ تصميم الحدائق ( الفضاءات الخارجية) جامعة بغداد 2015م) )

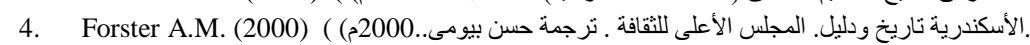

5. Gidens, A. Modernity and Self-Identity, Stanford University Press , California; 1991.

6. Goodwin EM. Classic Mosaic Designs and Projects Inspired by 6000 years of Mosaic Art, London; 2000.

7. Raafat, A., Mediterranean sea A cultural unifier lake in cycles, Shared Mediterranean Heritage; 2014.

8. Usery, HM., Hafez, BB, Mohamed, B. (2010). حسن محمود يسرى ، بكرى بهاء الدين حافظ ، بهاء الدين محمد وآخرون.الاليل الإرشادى أسس ومعايير )

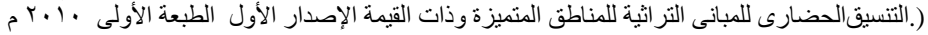

9. Weeks JM.and De Medeiros, J. A research Guide to The Ancient World, Row man \&Littlefield, London; 2015.

10. http://vancouver.ca/files/cov/park-board-mural-guidelines.pdf

11. https://www.ura.gov.sg/uol/uol//media/User\%20Defined/URA\%20Online/Guidelines/Conservation/Cons-Guidelines.pdf

12. https://ar.wikipedia.org

13. http://journals.sagepub.com

14. https://www.pinterest.com

15. https://uk.pinterest.com

16. https://www.flickr.com

17. http://www.museumoflondonimages.com

18. http://www.gettyimages.com/

19. http://www.rahalat.net/ 